NASA/TM-2003-212180

Blade Row Interaction Effects on the Performance of a Moderately Loaded NASA Transonic Compressor Stage

Dale E. Van Zante

Glenn Research Center, Cleveland, Ohio

Wai-Ming To

AP Solutions, Inc., Cleveland, Ohio

Jen-Ping Chen

Mississippi State University, Mississippi State University, Mississippi 
Since its founding, NASA has been dedicated to the advancement of aeronautics and space science. The NASA Scientific and Technical Information (STI) Program Office plays a key part in helping NASA maintain this important role.

The NASA STI Program Office is operated by Langley Research Center, the Lead Center for NASA's scientific and technical information. The NASA STI Program Office provides access to the NASA STI Database, the largest collection of aeronautical and space science STI in the world. The Program Office is also NASA's institutional mechanism for disseminating the results of its research and development activities. These results are published by NASA in the NASA STI Report Series, which includes the following report types:

- $\quad$ TECHNICAL PUBLICATION. Reports of completed research or a major significant phase of research that present the results of NASA programs and include extensive data or theoretical analysis. Includes compilations of significant scientific and technical data and information deemed to be of continuing reference value. NASA's counterpart of peerreviewed formal professional papers but has less stringent limitations on manuscript length and extent of graphic presentations.

- TECHNICAL MEMORANDUM. Scientific and technical findings that are preliminary or of specialized interest, e.g., quick release reports, working papers, and bibliographies that contain minimal annotation. Does not contain extensive analysis.

- CONTRACTOR REPORT. Scientific and technical findings by NASA-sponsored contractors and grantees.
- CONFERENCE PUBLICATION. Collected papers from scientific and technical conferences, symposia, seminars, or other meetings sponsored or cosponsored by NASA.

- SPECIAL PUBLICATION. Scientific, technical, or historical information from NASA programs, projects, and missions, often concerned with subjects having substantial public interest.

- TECHNICAL TRANSLATION. Englishlanguage translations of foreign scientific and technical material pertinent to NASA's mission.

Specialized services that complement the STI Program Office's diverse offerings include creating custom thesauri, building customized databases, organizing and publishing research results ... even providing videos.

For more information about the NASA STI Program Office, see the following:

- Access the NASA STI Program Home Page at http://www.sti.nasa.gov

- E-mail your question via the Internet to help@sti.nasa.gov

- Fax your question to the NASA Access Help Desk at 301-621-0134

- Telephone the NASA Access Help Desk at 301-621-0390

- Write to:

NASA Access Help Desk

NASA Center for AeroSpace Information 7121 Standard Drive

Hanover, MD 21076 
NASA/TM-2003-212180

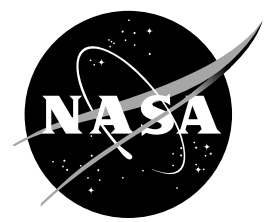

\section{Blade Row Interaction Effects on the Performance of a Moderately Loaded NASA Transonic Compressor Stage}

Dale E. Van Zante

Glenn Research Center, Cleveland, Ohio

Wai-Ming To

AP Solutions, Inc., Cleveland, Ohio

Jen-Ping Chen

Mississippi State University, Mississippi State University, Mississippi

Prepared for the

Turbo Expo 2002

cosponsored by the American Society of Mechanical Engineers

and the International Gas Turbine Institute

Amsterdam, The Netherlands, June 3-6, 2002

National Aeronautics and

Space Administration

Glenn Research Center 


\section{Acknowledgments}

Thank you to Tony Strazisar, John Adamczyk, and Louis Larosiliere for discussions of blade row interaction mechanisms and compressor design methods. Thank you to Tim Beach for assistance with gridding and interpolation software.

Available from

NASA Center for Aerospace Information 7121 Standard Drive

Hanover, MD 21076
National Technical Information Service 5285 Port Royal Road Springfield, VA 22100

Available electronically at http:/ /gltrs.grc.nasa.gov 


\title{
Blade Row Interaction Effects on the Performance of a Moderately Loaded NASA Transonic Compressor Stage
}

\author{
Dale E. Van Zante \\ National Aeronautics and Space Administration \\ Glenn Research Center \\ 21000 Brookpark Road \\ Cleveland, $\mathrm{OH} 44135$ \\ Wai-Ming To \\ AP Solutions, Inc. \\ 21000 Brookpark Road \\ Cleveland, $\mathrm{OH} 44135$ \\ Jen-Ping Chen \\ Engineering Research Center \\ Mississippi State University \\ Mississippi State University, MS 39762
}

\begin{abstract}
Blade row interaction effects on loss generation in compressors have received increased attention as compressor work-per-stage and blade loading have increased. Two dimensional Laser Doppler Velocimeter measurements of the velocity field in a NASA transonic compressor stage show the magnitude of interactions in the velocity field at the peak efficiency and near stall operating conditions. The experimental data are presented along with an assessment of the velocity field interactions. In the present study the experimental data are used to confirm the fidelity of a three-dimensional, time-accurate, Navier Stokes calculation of the stage using the MSU-TURBO code at the peak efficiency and near stall operating conditions. The simulations are used to quantify the loss generation associated with interaction phenomena. At the design point the stator pressure field has minimal effect on the rotor performance. The rotor wakes do have an impact on loss production in the stator passage at both operating conditions. A method for determining the potential importance of blade row interactions on performance is presented.
\end{abstract}

\section{INTRODUCTION}

The performance of compressors and the sophistication of analysis tools have reached a level such that less well understood flow mechanisms are gaining in importance to designers. The impact on compressor performance of many of these mechanisms, such as blade row interactions, is not typically addressed in current design systems. Although attempts were made to quantify the impact of these mechanisms (for example Kemp and Sears [1]) more than 40 years ago, measurement and computational methods have only recently advanced to an extent that allows a more definitive analysis. See Hathaway [2], Smith [3], and Van Zante [4] among others, for an overview of research on a wide range of unsteady phenomena.

The database of time-resolved velocity measurements in high-speed machines suitable for assessing blade row interactions is small. An early and notable set of data were acquired by Ding [5] in a closely-coupled, 3-stage, transonic axial compressor. He noted 'violent flow acceleration and deflection across an axial distance of only $4 \mathrm{~mm}$ ' from measurements taken between stator 2 and rotor 3 of the compressor. The measurements hint at the possibility for interaction effects to be significant in some machines. Other data sets of note include that of Williams [6] in a close-coupled, multi-stage, high-speed compressor, Hathaway [2] in a looselycoupled transonic fan stage, Ottavy, et al. [7] of IGV-transonic rotor interaction in an HP compressor stage, and Estevadeordal et al. [8] for DPIV measurements of IGV-transonic rotor interaction.

The above mentioned data do not provide a direct measure of thermodynamic quantities from which loss can be calculated. The time and length scales in turbomachinery flows have so far precluded these types of measurements although development continues in the area of time-accurate non-intrusive state variable measurements (for example Berreby, et al, [9]). A rational approach to quantifying losses due to blade row interactions is to use a detailed set of experimental data to aid in the setup and verification of the time-resolved velocity field of a numerical computation. A detailed set of 2D LDV rotor wakestator interaction data acquired in a NASA transonic compressor stage and the resulting time-accurate computations are presented here. 
Recent computational work on blade row interactions includes that of Epstein et. al [10] who looked at spatial variations in flow properties downstream of a high speed rotor due to the potential field of the downstream stator. NASA Stage 67 was the compressor geometry used. This work used the LDV data of Hathaway [2] and numerical results from a 2D inviscid time-accurate computation. Rotor/stator spacing and the ratio of rotor pitch to stator pitch were found to have a significant influence on the magnitude of the variations. Stator loading had only a minor influence. For rotor/stator spacings typical of high bypass ratio turbofans the non uniformities are negligible. Epstein et. al used the Stage 67 geometry to do a parametric study of the interactions at a range of rotor/stator spacings and pitch ratios typical of HP compressors. The numerical calculations for spacings typical of HP compressors showed the possibility of large circumferential variation of rotor flowfield properties due to back pressure from the stator. Interestingly, the variations in total temperature and total pressure were found to be in phase so the variation in adiabatic efficiency due to nonuniform rotor exit properties was small as long as the measuring instrumentation was located in identical locations relative to the stator blade.

Valkov and Tan [11] examined the influence of rotor wakes and the rotor tip clearance flow on the performance of a downstream stator. They found two opposing mechanisms at work in the stator passage: 1) beneficial 'recovery' of the disturbance energy of both the wake and clearance vortex due to vortex stretching in the stator and 2) an increase in loss due to distortion of the stator boundary layers because of the disturbance velocity field created by the upstream blade row. Overall the benefit of recovery was greater than the increase in stator boundary layer interaction loss for the geometry considered. Rotor/stator spacing and the frequency of rotor wake fluctuations (such as vortex shedding) had a significant influence on benefit/loss ratio. The benefit of recovery relative to loss increased as the rotor/stator spacing was decreased. Stator loading distribution had a second order effect. The magnitude of the velocity disturbance entering the downstream stator has an important influence on the profile losses of the stator. This work confirms that interaction mechanisms can be important and is evidence that the velocity non-uniformity at the stator inlet is a characteristic parameter of the interaction strength. The stator influence on rotor loss production was not considered in this work.

Loss generation due to blade row interactions is a coupled problem. In a compressor stage, for example, the stator generates a pressure pulse as a gust response from chopping the rotor wake. The pressure pulse interacts with the upstream rotor which in turn responds to its altered downstream boundary condition. The result is a complex flowfield where it is difficult to distinguish between cause and effect. This coupling of the rotor and stator is well known in fan acoustics but has yet to be analyzed for its possible impact on HP compressor performance even though contemporary compressor designs have highlyloaded, tightly-coupled blade rows. The simulations done in the above references were setup in such a way that the blade rows were not fully coupled because of the difficulty in de-coupling the individual mechanism influences on loss production. For example, in Valkov and Tan the rotor wake character was prescribed and held constant with circumferential position relative to the stator. This allowed the authors to assess stator losses for a particular rotor wake but ignored possible additional losses due to the stator potential field causing changes in the rotor wake with circumferential position.

The present work focuses on answers to the following questions for a high-speed, closely-coupled, moderately-loaded, compressor stage:

1. Does the stator have a significant influence on rotor loss production?

2. Do the rotor wakes and rotor tip clearance flow have a significant influence on stator loss production?

From a design viewpoint, knowing when to consider interaction effects on performance may be more important than knowing what the fluid mechanics of the interaction mechanisms are. Therefore, a simpler approach is proposed for determining the strength of interactions [Capece, 12]. The unsteady change in static pressure, $\Delta P_{\text {static }}$, at a blade row exit is a measure of a downstream blade row's influence. The unsteady $\Delta P_{\text {static }}$ would encompass effects such as the potential field of a downstream stator or the bow wave of a downsteam transonic rotor. The unsteady change in velocity (disturbance flow is the term used by Valkov and Tan), $\Delta V$, due to wakes or clearance flow is a measure of the upstream blade row's influence on the downstream blade. Both $\Delta P_{\text {static }}$ and $\Delta V$ are estimable from a steady flow simulation, APNASA in this case. Changes in loss due to interactions will be determined from the unsteady calculation and correlated with $\Delta V$ and $\Delta P_{\text {static }}$. The goal is to determine what regimes of operation as characterized by $\Delta P_{\text {static }}$ and $\Delta V$ result in significant interactions which may be detrimental to compressor performance or which may invalidate results from design systems which do not account for these interactions.

This paper is organized as follows. The experimental setup, the numerical codes used, and the loss analysis techniques are described first. Detailed 2D LDV measurements are shown next and some preliminary analysis of the magnitude of the blade row interactions is done using the LDV data alone. These measurements were used in a previous study to assess performance effects due to wake chopping/transport phenomena in the stator [Van Zante, et al., 13]. The setup and validation of the MSU-TURBO simulation is shown next. Finally the loss production in the stage is analyzed using both the steady and time accurate simulation results. 


\section{EXPERIMENTAL SETUP}

The LDV measurements were acquired in the NASA Glenn Research Center single-stage axial-flow compressor facility. The test stage consisted of NASA rotor 35 and NASA stator 37. The rotor had 36 blades and was operated at a tip clearance of $0.58 \mathrm{~mm}$ ( $1.0 \%$ of tip axial chord). The stator had 46 vanes and also had a tip clearance gap at the casing of $0.48 \mathrm{~mm}$ to accommodate the LDV window. Details of the blading design are in Reid and Moore [14].

The hybrid stage (rotor 35/stator 37) was used because NASA rotor 37 was damaged by the implosion of an LDV window early in the test program. Rotor 35 was matched to stator 37 by restaggering the stator 4 degrees open and by operating the stage at $80 \%(363 \mathrm{~m} / \mathrm{s}$ tip speed) of design speed to avoid choking problems in the stator. LDV data and aero performance data were acquired at both the peak efficiency (PE) and near stall (NS) operating conditions.

A large window, which conformed to the 3D shroud contour, provided optical access to the flowfield from one rotor chord upstream of the rotor to one stator chord downstream of the stator. LDV measurements were acquired at $75 \%$ span from the hub across one stator pitch as shown in Figure 1. Detailed pitchwise surveys were acquired from the rotor trailing edge through $20 \%$ stator chord, and at $50 \%, 90 \%, 110 \%$, and $120 \%$ stator chord. Typically there were 15 to 18 measurement locations in a pitchwise survey at each axial position. The $110 \%$ stator chord plane is the closest to the stator trailing edge where a complete pitchwise data survey was acquired and thus is used as the stator exit condition. The LDV data were acquired phase locked to rotor position. The data were then ensemble averaged to a single rotor blade passing. One rotor blade passing is divided into 184 measurement windows. The error in the LDV measurements is approximately $\pm 1.0 \mathrm{~m} / \mathrm{s}$ for absolute velocity and \pm 0.5 degrees in absolute flow angle. For more detail on the LDV measurements and aero performance measurements see Van Zante, et. al [4].

\section{NUMERICAL CODES}

Three-dimensional steady Reynolds Averaged Navier-Stokes (RANS) simulations of the compressor stage were done with APNASA (version 1.13) developed by Adamczyk [15]. APNASA is a unique multi-stage turbomachinery solver that models the influence of neighboring blade rows by the use of body forces and deterministic stress terms. This approach does not utilize a mixing plane between blade rows. Instead, the mesh domain for each blade row encompasses both its previous and following blade row. The axisymmetric influence of the neighboring blade rows appears as body forces within the upstream and downstream extents of the computation domain. Additional unsteady interaction effects are simulated by closure

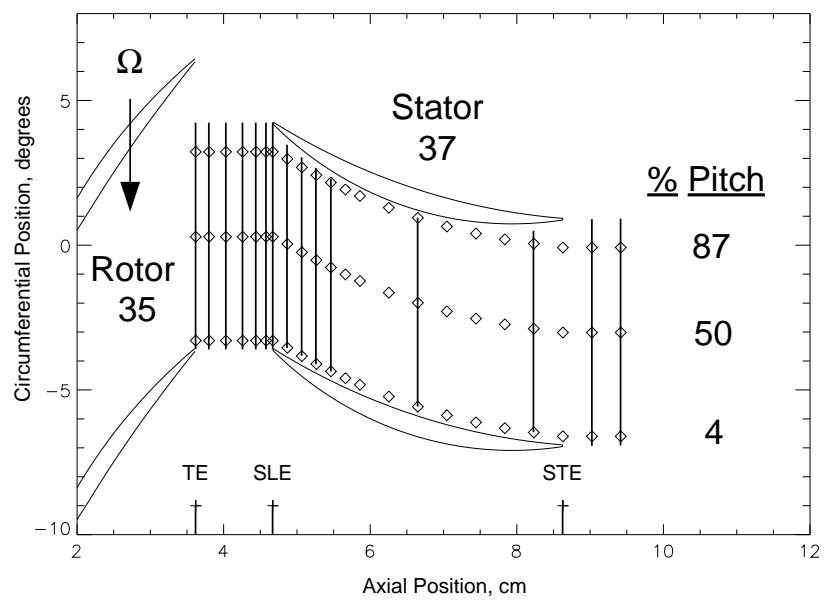

Figure 1. LDV data measurement locations.

models for the deterministic stress terms that arise from Adamczyk's decomposition of the Navier Stokes equations. However, not all interaction mechanisms are currently captured by this approach (wake chopping and transport for example), thus the motivation for the current work.

APNASA uses a modified $k-\varepsilon$ turbulence model which is described in Shabbir, et al [16]. Sheared H-meshes were used and had 81 nodes along the blade chord and 71 nodes radially. The rotor had 9 cells and the stator had 8 cells across the clearance gap at the casing. The cells were packed at the casing in both blade rows to capture the wall bounded shear layer so that the rotor tip clearance flow is accurately simulated [17]. The rotor had 51 nodes and the stator 79 nodes in the circumferential direction. The distance of the first node tangentially from the blade surface was chosen to give good mesh quality as well as be consistent with the wall function assumption in the turbulence model. The measured total pressure and total temperature profile was used as the upstream boundary condition for the simulation. A hub static pressure and radial equilibrium were used for the outflow boundary. The steady simulation flow fields were used as the starting solution for the time accurate calculations which results in a large savings in computation time for the time accurate simulations [19].

Time-accurate solutions were generated using MSU-TURBO which solves the unsteady RANS equations along with decoupled $k-\varepsilon$ equations. The $k-\varepsilon$ model is the same formulation as is used in APNASA. Extensive and as yet unpublished comparisons were done to validate the operation of the $k-\varepsilon$ model in TURBO. The parallel computation version of TURBO was used [18]. The parallel code allows computations with grids of sufficient size to allow realistic simulations in a reasonable amount of time. The size of the intra-blade row meshes are now of the same or higher density than the steady flow calculation meshes. TURBO also incorporates a time-shifted boundary condition that allows calculations with actual blade counts using 
a single passage for each blade row [19]. The peak efficiency simulation used 1D non-reflecting boundary conditions with a base flow determined from the APNASA simulation. The near stall simulation was more difficult to obtain and required using a prescribed total pressure and total temperature profile at the inlet and a hub static pressure with radial equilibrium at the exit.

Careful attention to mesh topology is necessary to achieve high quality simulations with time-accurate codes. The Average Passage Grid (APG) generator of Beach [20] was used to build the rotor and stator meshes for the TURBO calculation. APG creates single block H-meshes which are elliptically smoothed in the blade-to-blade direction. This allows better definition of leading and trailing edges and eliminates the high aspect ratio cells at the blade inlet and exit planes which are a consequence of the sheared H-mesh topology. The elliptic smoothing distributes nodes more uniformly at mid pitch and thus results in meshes which are better able to capture flow features which convect or propagate into the domain of one blade row from neighboring blade rows.

The rotor mesh for the TURBO calculation has 81 nodes on the blade chord, 71 nodes radially with 10 cells in the clearance gap, and 55 nodes in the circumferential direction (600,376 total nodes). The stator has 81 nodes on the blade chord, 71 nodes radially with 9 cells in the clearance gap, and 79 nodes in the circumferential direction $(790,869$ total nodes). The distance of the first node tangentially from the blade surface was set the same as the APNASA mesh. To maintain higher grid density in the rotor wakes, the rotor/stator mesh interface was located slightly downstream of mid rotor/stator gap. The inlet to the stator mesh has equally spaced cells in the tangential direction which are of approximately the same size as the rotor mesh cells in the wake region. This assures approximate matching of nodes across the mesh block interface so that the rotor wake is convected across it with minimal dissipation due to interpolation. The TURBO calculation used 160 time steps per rotor blade passing with 6 Newton subiterations per time step.

Figure 2 shows the computational mesh boundaries relative to the blading for both the APNASA and TURBO simulations. The TURBO mesh has smaller axial extents to reduce the computational resources needed. The rotor/stator gap varies from $21.2 \%$ of stator hub axial chord to $32.4 \%$ of stator tip axial chord from hub to tip respectively.

Table 1 shows the aeroperformance of the stage from the experiment and from the simulations. The simulations were converged to the same mass flow as the experiment operating conditions. APNASA and TURBO are in good agreement for pressure ratio and temperature ratio while the respective data show lower values for the stage at both operating conditions. The stator blades for which the LDV and aeroperformance data were acquired were attached at the hub and were thickened for structural reasons in the lower $40 \%$ of span relative to the design stator 37 . The geometry used for the simulations was the 'as

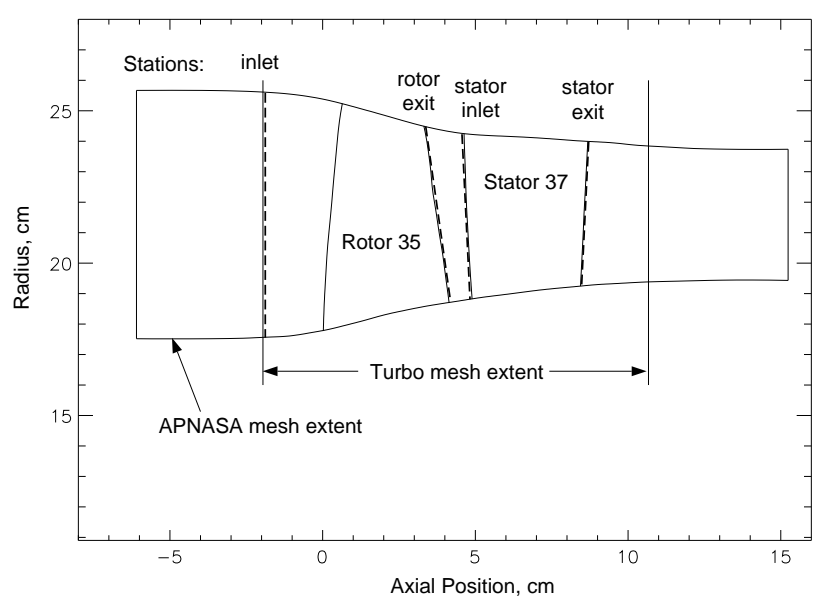

Figure 2. Computational mesh extents and stations used for loss analysis.

designed' stator 37. This difference may account for some of the discrepancy between the experiments and simulation aero performance. The details of the experimental setup and measurements of passage to passage periodicity are in Van Zante [4]. Details of the velocity field (wake width and depth) at $75 \%$ span where the LDV data were acquired will not be significantly affected by this small change in geometry. Consequently, the LDV data are used to validate the kinematics of the TURBO simulation velocity fields to insure mesh topology is adequate to capture the rotor wake behavior. The loss analysis for the stage is then done using only the simulations because they are self consistent.

Table 1: Aeroperformance of the stage.

\begin{tabular}{|c|c|c|c|c|c|}
\hline & $\begin{array}{l}\text { Mass } \\
\text { flow, kg/s }\end{array}$ & $\begin{array}{l}\text { Pressure } \\
\text { Ratio }\end{array}$ & $\begin{array}{l}\text { Temp. } \\
\text { Ratio }\end{array}$ & $\begin{array}{l}\text { Adiabatic } \\
\text { Effi- } \\
\text { ciency }\end{array}$ & $\begin{array}{l}\text { Input } \\
\text { Power, } \\
\text { kW }\end{array}$ \\
\hline \multicolumn{6}{|c|}{ Experiment } \\
\hline PE & 17.2 & 1.40 & 1.113 & 88.5 & \\
\hline NS & 15.1 & 1.49 & 1.148 & 81.0 & \\
\hline \multicolumn{6}{|c|}{ APNASA } \\
\hline $\mathrm{PE}$ & 17.1 & 1.44 & 1.126 & 87.6 & 624 \\
\hline NS & 15.2 & 1.52 & 1.154 & 81.8 & 683 \\
\hline \multicolumn{6}{|c|}{ TURBO } \\
\hline PE & 17.2 & 1.46 & 1.130 & 87.1 & 648 \\
\hline NS & 15.2 & 1.54 & 1.161 & 81.8 & 707 \\
\hline
\end{tabular}

\section{STAGE LDV DATA}

The LDV data have the temporal and spatial resolution necessary for a detailed evaluation of the wake/blade interaction. Figure 3 shows rotor wakes inside of the stator 

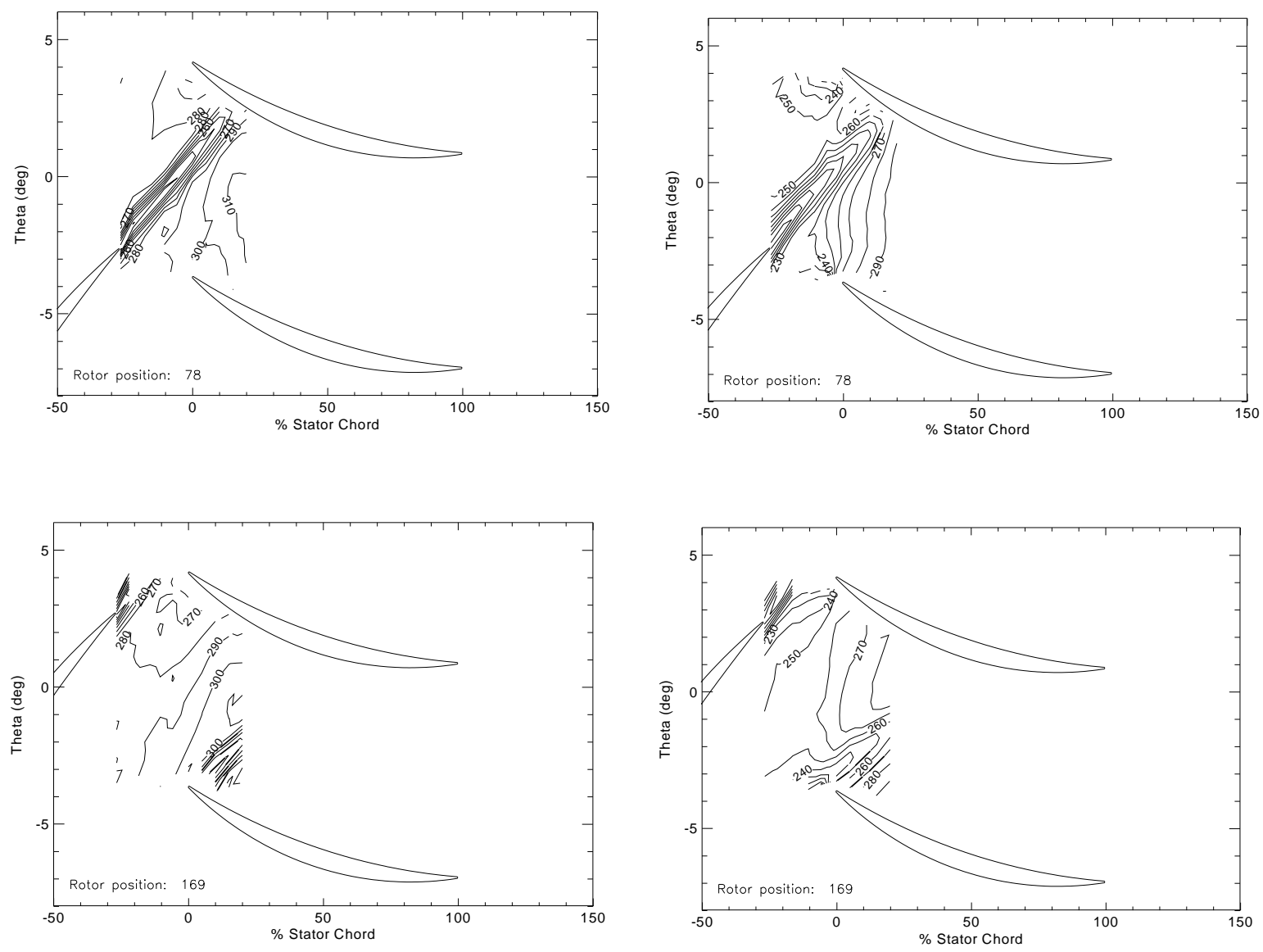

A. Peak Efficiency

B. Near Stall

Figure 3. Relative velocity magnitude $(\mathrm{m} / \mathrm{s})$ at two rotor/stator orientations from LDV data.

passage at two rotor/stator positions for both measured operating conditions. The time resolution of the data is 184 time steps (data windows) per rotor blade pitch. The limited spatial resolution of the data results in some lack of smoothness in the contour lines. The upper plots in the figure show the first rotor position. Part A shows that the peak efficiency rotor wake is a narrow, well defined region and it remains so to nearly the suction surface of the stator. The near stall wake shown in Part B is wider and of about the same depth, but shows a stronger interaction with the leading edge region of the stator. The scale of the figure precludes a detailed view of the attenuation near the suction surface due to the gust response of the stator. However, by following along the wake centerline it can be seen that the near stall wake deficit is attenuated more rapidly than the peak efficiency wake as the suction surface is approached. It is also evident that the stator is more forward loaded at the near stall operating condition as seen in the freestream velocity gradients and the enlarged stator leading edge stagnation region. The lower plots of Figure 3 show the rotor wake at or near being chopped by the lower stator blade. The peak efficiency wake interaction with the stator leading edge is again minimal. The near stall rotor wake is greatly attenuated and, by tracing the wake centerline, it is apparent that the wake is already being tilted and stretched in the stator passage as compared to the peak efficiency case.

\section{Rotor losses}

The influence of the stator potential field on the rotor appears in the LDV data in two ways: 1) a variation of time average absolute velocity relative to stator position at the rotor trailing edge plane and 2) a variation of rotor wake characteristics (depth/width) relative to stator position. Figure 4 shows that the variation of time-average absolute velocity with stator pitch is $\pm 3 \mathrm{~m} / \mathrm{s}$ for peak efficiency and $\pm 6 \mathrm{~m} / \mathrm{s}$ for near stall. Assuming that the velocity variations are small compared to freestream velocity, the variation in static pressure can be estimated as (assuming constant time average total temperature):

$$
\frac{P}{P_{\infty}} \cong 1-\gamma M_{\infty}^{2} \frac{\Delta V}{V_{\infty}}
$$

For the near stall case, assuming a nominal freestream Mach number of 0.55 , a freestream velocity of $150 \mathrm{~m} / \mathrm{s}$, and a $\Delta V$ of 


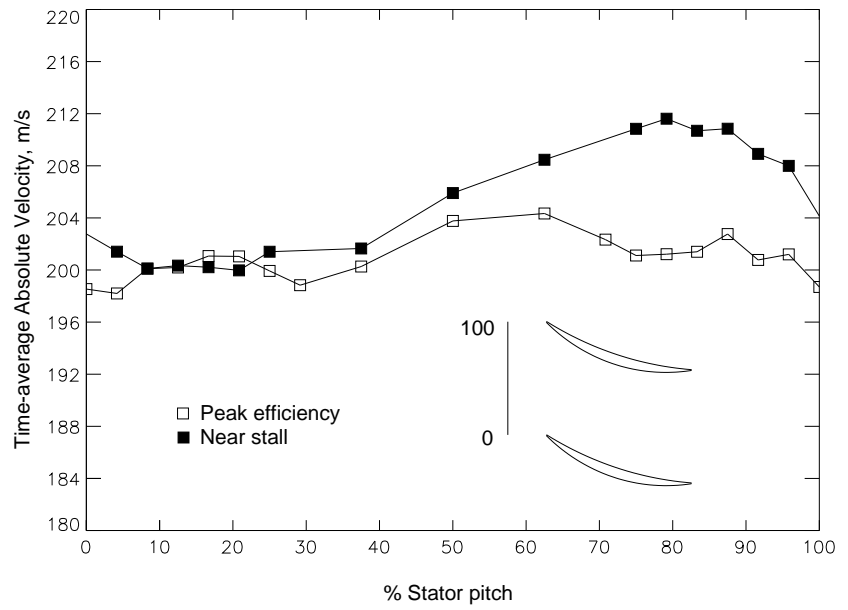

Figure 4. Time average absolute velocity at $75 \%$ span, rotor trailing edge axial location from the LDV data.

$\pm 6 \mathrm{~m} / \mathrm{s}$ the ratio of $P / P_{\infty}=1.0 \pm 0.017$. This variation in rotor

back pressure is $\pm 6 \%$ of the static pressure rise through the rotor. At peak efficiency the variation is $\pm 2 \%$ of static pressure rise through the rotor. The influence of this back pressure variation on rotor loss production (if any) will be quantified in a later section.

Variations of the rotor wake profiles near the rotor trailing edge with circumferential location would be another indication of an influence of the downstream stator. Figure 5a shows the rotor wake at different circumferential locations at approximately $105 \%$ rotor axial chord. This is a difficult region in which to acquire data due to high window curvature and seed contamination of the window surface. Some additional scatter and reduction in data quality are to be expected. Only the axial component of the velocity is shown. The plots of the tangential velocity are in the appendix of ref. [4]. The peak efficiency wakes show little variation in width or depth with spatial location. The freestream velocity shows a small variation as would be expected from the variation in time average absolute velocity. The similarity of the wakes indicates that the stator potential field has minimal effect of rotor loss production at the peak efficiency condition even for this closely coupled highspeed compressor stage.

The wakes at the near stall operating condition show a greater variation with position relative to the stator, Figure $5 \mathrm{~b}$, which indicates that the presence of the stator is influencing the rotor. The pressure surface boundary layer seems unaffected but the suction surface boundary layer shows increased thickness. The freestream shows greater variation as expected also. The increased suction surface boundary layer thickness may indicate increased rotor losses at certain rotor/stator positions. A change in rotor loss with circumferential position (if any) will be quantified using numerical simulations.

Figure 6 compares the wake profiles for LDV data and CFD

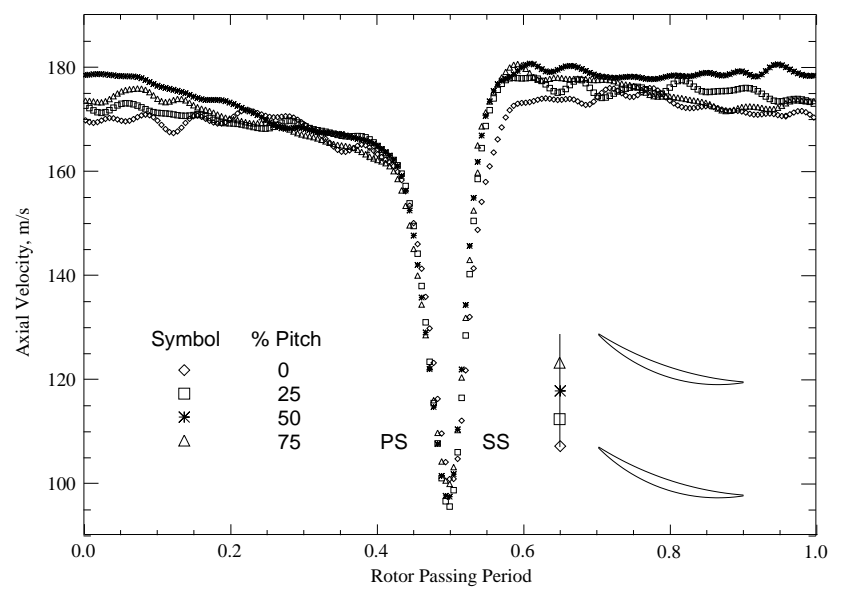

a.)

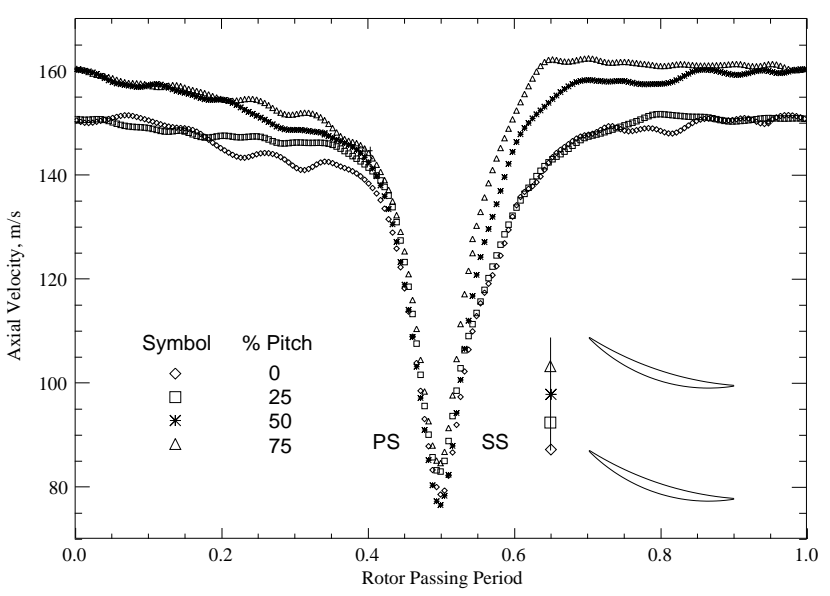

b.)

Figure 5. Wake profiles at the rotor trailing edge at $75 \%$ span from the LDV data. a.) Peak efficiency. b.) Near stall.

results at the rotor trailing edge. The TURBO wake comparison is done for the rotor trailing edge at the $50 \%$ stator pitch location. As is characteristic for CFD calculations in general [21,22], TURBO and APNASA show a very deep wake compared to the LDV data. The nature of LDV data acquisition and ensemble averaging could account for most of this difference in wake depth very near the rotor trailing edge. LDV data acquisition does not give a velocity trace which is continuous with time because an LDV measurement is only acquired when a seed particle passes through the probe volume. Each velocity is tagged with the rotor angular position using a shaft angle encoder and placed in the proper measurement window. Measurements are processed to obtain an average for each window and then ensemble averaged across one blade pitch to yield an average passage. Therefore, blade-to-blade geometry differences, vortex shedding, or other nonsynchronous motion of the rotor wake will broaden the ensemble average rotor wake and decrease the wake depth. The 


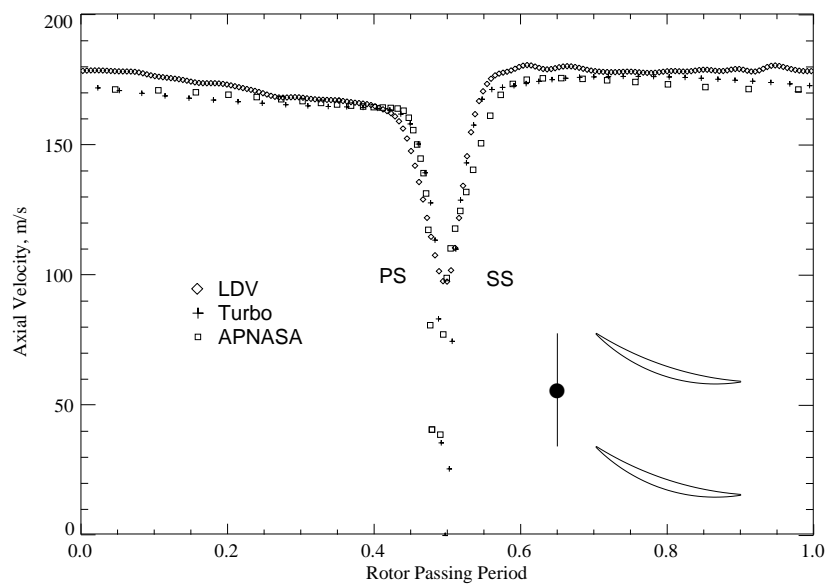

a.)

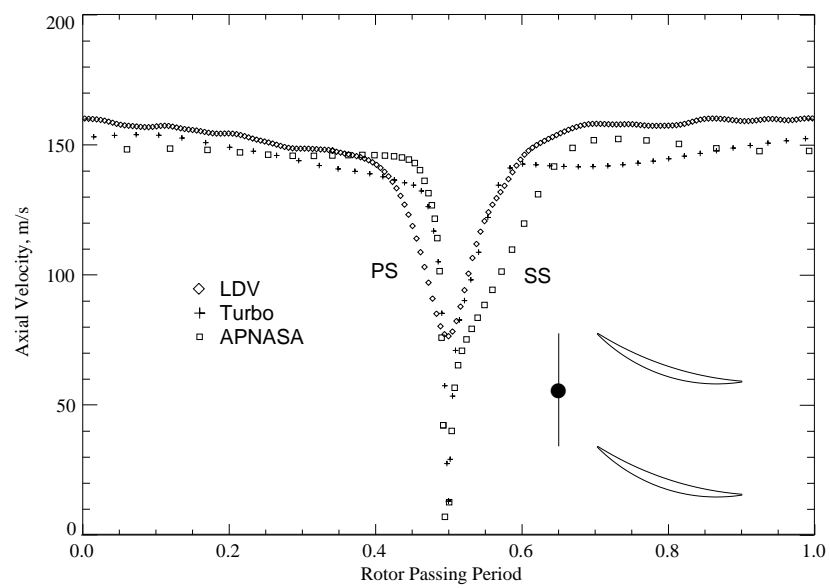

b.)

Figure 6. Rotor wake profile comparison at the rotor trailing edge, $75 \%$ span, (the rotor trailing edge is at $50 \%$ stator pitch for the TURBO data). a.) peak efficiency b.) near stall.

deep narrow wake near the rotor trailing edge is especially susceptible to these effects. Consequently, the agreement is quite good for wake width and freestream velocity for peak efficiency but marginal for the near stall simulation.

\section{Stator losses}

Figure 7 shows the rotor wake profiles at the stator leading edge plane for peak efficiency and near stall. Again, only the axial velocity component is shown here. The wake axial velocity deficit is $24 \%$ and $23 \%$ of freestream for peak efficiency and near stall respectively at the stator midpitch location.

Figure 7 also compares the wake profiles of LDV and CFD at the stator leading edge. Note the good comparison between data and simulation indicating that the simulations have the correct disturbance velocity field entering the stator. The TURBO results are taken from the nearest node to the experimental data

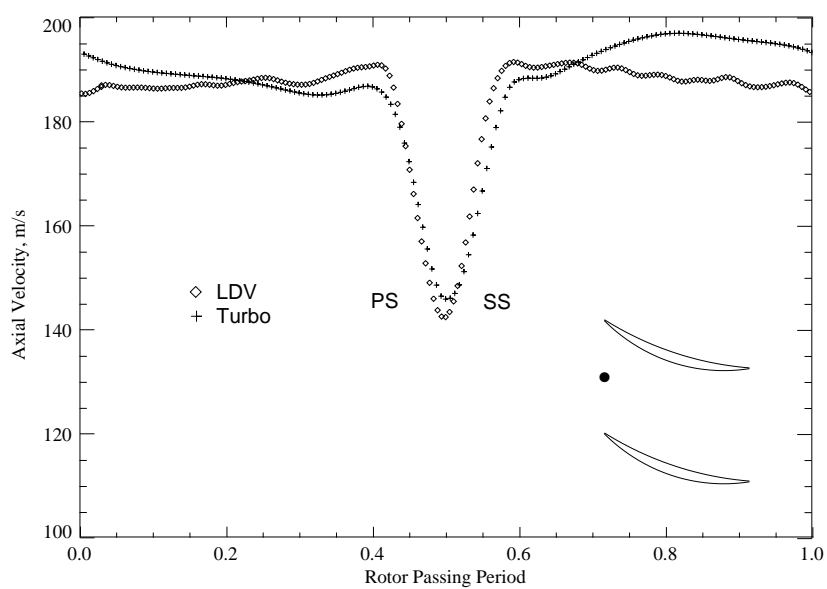

a.)

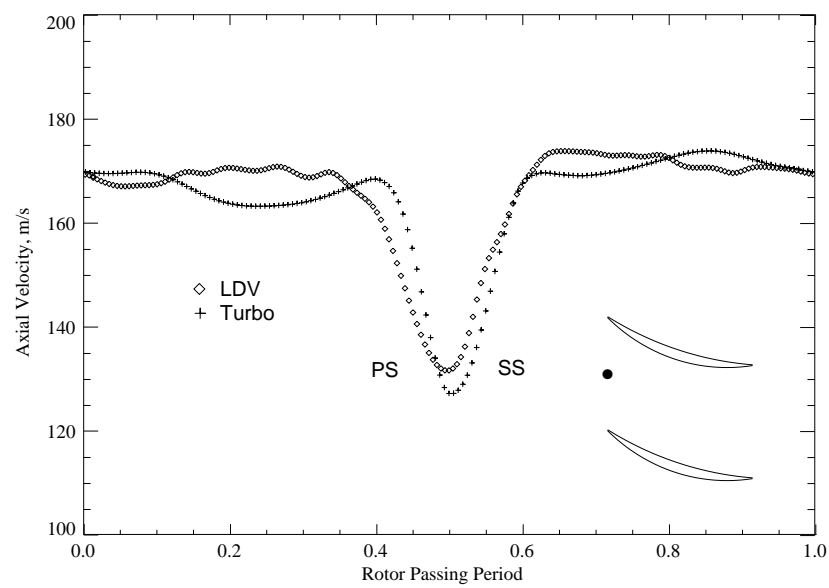

b.)

Figure 7. Wake profiles at the stator leading edge plane, $75 \%$ span, $50 \%$ stator pitch. a.) Peak efficiency. b.) Near stall.

measurement point.

Figure 8 shows the remaining wake signature at the $110 \%$ stator chord location. At mid pitch, the near stall wake is nearly completely attenuated while the peak efficiency wake still shows identifiable structure. The wakes go through similar viscous dissipation but the near stall wake is stretched substantially more in the stator passage thus resulting in its greater attenuation [13].

Figure 8 also compares the wake profiles near the stator exit to TURBO results. The simulations again show reasonable comparison to data. This indicates adequate grid density throughout the stator passage to capture the wake behavior.

It is difficult to determine the influence of the rotor wakes on the stator loss by using only LDV measurements. LDV measurements of the stator wake region do show variations due to the convected rotor wakes but much greater spatial resolution would be necessary to measure changes in the stator boundary 
layer character. To analyze the stator performance and to quantify the rotor performance influences analysis of a numerical simulation is necessary.

\section{LOSS ANALYSIS}

The TURBO solutions are analyzed using the concept of irreversibility which comes from the field of availability analysis. The ideas and thermodynamics behind availability analysis are discussed in detail in VanWylen and Sonntag [23]. Typically the performance of a device such as a compressor is rated using an energy based or first law efficiency. For example, adiabatic efficiency is derived from comparing the actual thermodynamic end state of a process to the fictitious end state for an isentropic compression process. Instead irreversibility looks at how much work would be done if the fluid went through the same change in state except in a completely reversible process. Irreversibility is the difference in work between the reversible and the actual process. VanWylen and Sonntag also use the term 'Lost Work' for the irreversibility that occurs in a process. For a compressor the irreversibility or lost work is the additional amount of work that is put into the machine to overcome the losses in reaching the actual end state condition.

For an adiabatic, steady-state, steady-flow (SS,SF) process the irreversibility, I, is:

$$
I=\sum T_{o} m_{e} s_{e}-\sum T_{o} m_{i} s_{i}
$$

For a SS,SF adiabatic process the irreversibility occurring in a control volume is defined as the difference in entropy flux at the exit and inlet multiplied by a reference temperature. In the availability analysis framework the losses occurring in a real process are recovered by a reversible heat engine interacting with the surroundings at a temperature $T_{o}$. Thus, irreversibility has units of power which are easily converted to physically understandable units such as horsepower or watts [24]. The choice of $T_{o}$ is not arbitrary and in this case is chosen as standard day, the inlet condition for the simulations.

Irreversibility has the advantages: 1. the actual process end states are used, 2. it is simple to calculate for compressors from the standard output data of a CFD simulation, 3. the results are in physically understandable units with a thermodynamic rational for having computed them that way. The disadvantages are: 1. CFD codes can give spurious entropy sources and numerical errors (the first law efficiency is also impacted by these errors), 2. entropy production can be computed directly from the viscous dissipation function and heat transfer across a temperature gradient [25] however, the information necessary to compute entropy production directly is not typically available in standard CFD simulation output. As a tool for quickly assessing losses in a design environment the advantages of using irreversibility outweigh the disadvantages.

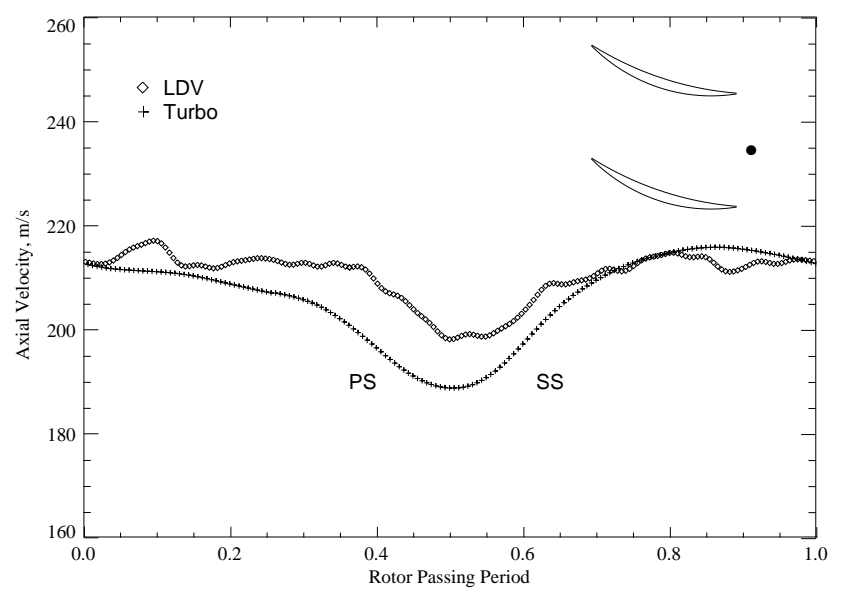

a.)

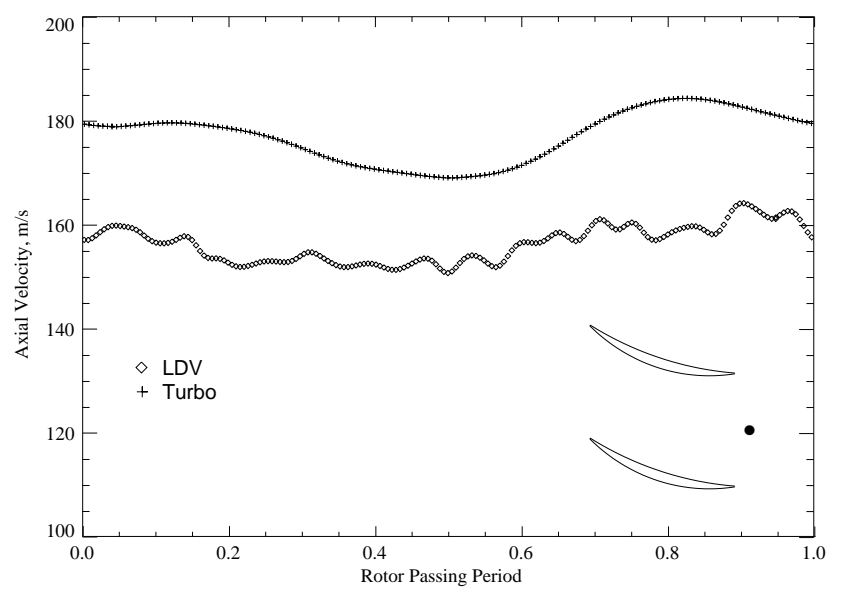

b.)

Figure 8. Wake profiles at stator trailing edge plane, $75 \%$ span, $50 \%$ pitch. a.) Peak efficiency. b.) Near stall.

\section{Time average loss}

Figure 9 shows the irreversibility for different axial locations through the compressor stage for the peak efficiency and near stall operating points. The inlet location corresponds to the axial position of the inlet to the TURBO mesh, see Figure 2. The rotor exit is the plane of the rotor trailing edge (not a constant axial position). Likewise the stator inlet and exit planes are at the blade edges. The TURBO results are presented as a time average loss which is calculated by averaging the loss at each time step. Figure 10 shows the change in irreversibility through the rotor, gap, and stator which makes differences in loss production more apparent. The total input power for each simulation at each operating condition is shown in Table 1.

Irreversibility relative to reference conditions is computed at the inlet plane. The results show slightly more loss (1.1-1.5kW) in the APNASA simulation inlet boundary layer. The flowfield at this location is steady in the relative frame so both the steady 


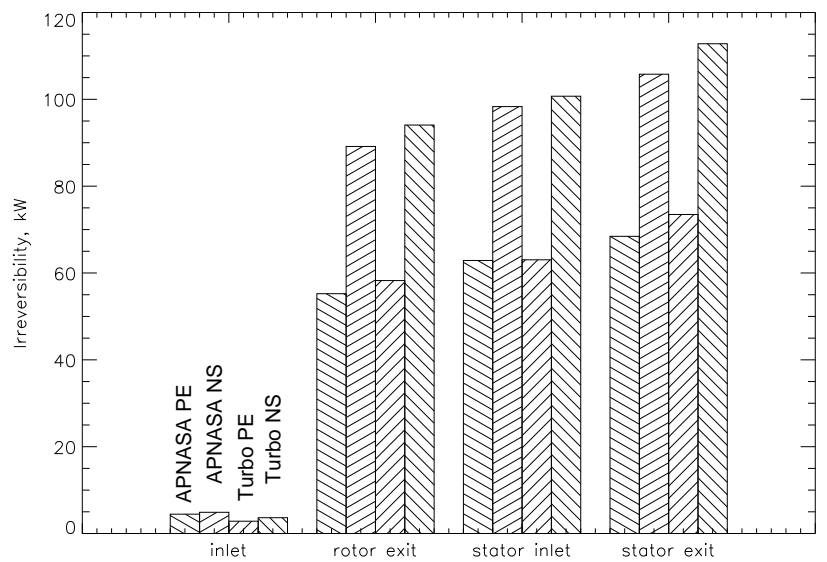

Figure 9. Loss (kW) at stations through the compressor stage.

and unsteady computations should yield identical results. Thus the inlet plane provides a measure of the magnitude of loss difference which might be considered significant.

The loss production in the rotor is similar for the simulations at each operating condition as shown by the results for the rotor exit station. It will be shown in the next section that the variation of loss with stator position is small therefore the loss production in the rotor should be similar for both steady and unsteady codes. For this compressor stage most of the loss production occurs in the rotor due to the shock, airfoil boundary layers including shock/boundary layer interaction, and tip clearance flow.

At the stator leading edge station the loss levels are nearly identical for both codes for each operating condition. The losses are brought into agreement by differences in the predicted loss production in the rotor/stator gap.

At the stator trailing edge station the TURBO results show a higher time average loss than APNASA for both operating conditions. When considered as a change in loss across the stator, the stator losses as predicted by TURBO are nearly double that of APNASA, see Figure 10. However the absolute value of the difference is relatively small so further investigation of the loss production in the stator is warranted to determine if the differences are real.

A loss audit of the stator passage is done at the peak efficiency condition to determine where the changes in loss production occurred. The stator passage is divided into five regions: tip boundary layer, hub boundary layer, pressure surface boundary layer, suction surface boundary layer, and the core flow. These regions were determined by examining the high entropy flow at the stator exit and selecting regions of the computation meshes that generally approximate these high entropy regions. The core flow included all but the high entropy regions. The irreversibility was calculated at the stator inlet and exit for each region. The loss production attributed to that region is the

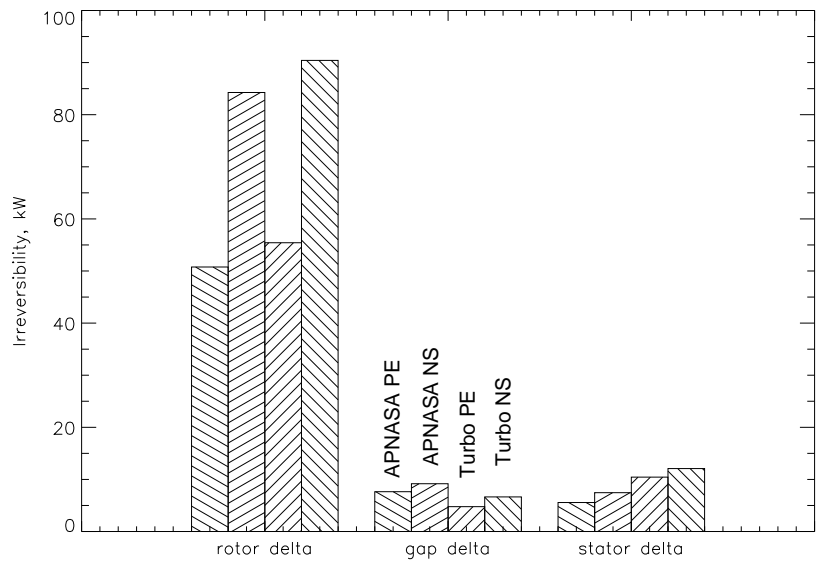

Figure 10. Loss production in the rotor, gap, and stator.

difference between inlet and exit irreversibility. This method does not account for radial or tangential migration of fluid in/out of the regions.

Figure 11 summarizes the results of this loss audit. For example, the tip region showed $2 \%$ less time average loss in the TURBO calculation than the APNASA results which indicates no significant change. The pressure surface boundary layer shows a very large increase in loss relative to APNASA. This loss difference is too large to be attributed to any changes in time mean incidence angle alone. This increase in loss is a combination of the rotor wake/stator boundary layer interaction, migration of rotor wake fluid to the pressure surface boundary layer and the wake/stator leading edge interaction. Figure 12 illustrates these phenomena with an instantaneous view of the entropy and disturbance velocity (instantaneous velocity - time average velocity) in the stator for the peak efficiency operating condition (see also Sanders, et al. [26]). The rotor wakes are clearly visible as regions of high entropy. The 'negative jet' behavior of the wake region can be seen in the disturbance velocity vectors. The high entropy rotor wake fluid migrates to the pressure surface of the stator and stator suction surface boundary layer fluid is drawn into the core flow. There are large disturbance velocities near the pressure surface near the stator leading edge also. There is increased loss production in this area relative to the steady simulation.

The rotor wake/stator leading edge interaction contributes approximately $50 \%$ of the additional pressure surface boundary layer loss in the TURBO calculation. This was determined by comparing the loss in the pressure surface boundary layer at $25 \%$ stator chord for the APNASA and TURBO solutions. The significant increase in loss at this location is attributable to the wake/stator interaction which is captured in the unsteady calculation.

Conversely, the suction surface boundary layer region has less loss production due to transport of suction surface boundary layer fluid to the core flow by the rotor wake/boundary layer 


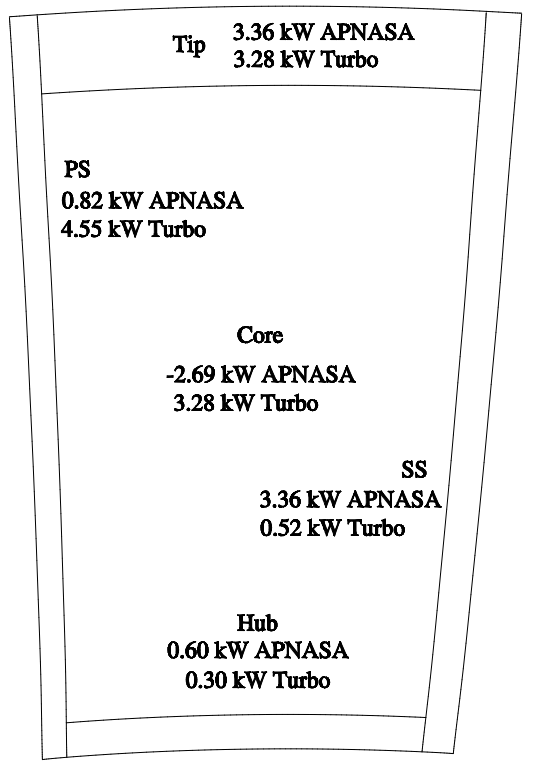

Figure 11. Loss audit at the stator exit location.

interaction. The net result for the stator passage is an increase in overall time average loss which is attributable to changes in stator loss production. The magnitude of the loss production changes are large enough to state that loss production in the stator has changed due to the rotor wake/stator interaction.

\section{Unsteady loss production}

Current design systems don't typically account for blade row interaction effects on loss production. A simple method for determining when a particular design may be at risk for incurring increased losses due to interactions would be valuable. For example, parameters easily determined from a steady simulation can be correlated with time varying loss amplitude from an unsteady simulation. Large unsteady loss amplitudes are an indication of strong interactions and could indicate that a steady analysis is inadequate to capture the necessary phenomena.

The influence of the stator on rotor unsteady loss production can be quantified by the variation of rotor loss production with stator position. Figure 13 shows the maximum variation in rotor loss as a function of back pressure variation. The variation in rotor loss is normalized by the time average rotor loss. The back pressure variation is calculated from the APNASA simulation as the maximum circumferential variation of static pressure at the rotor trailing edge at $50 \%$ span normalized by the rotor static pressure rise. The variation of rotor loss with stator position is very small for all cases. This is consistent with the results of Figure 9 which show no significant differences between

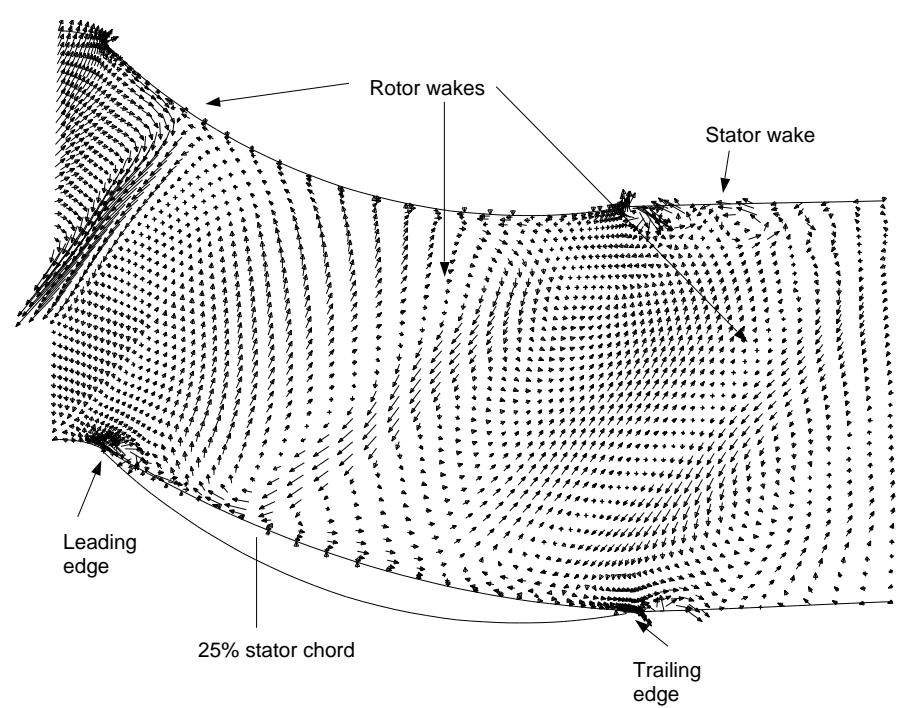

a.)

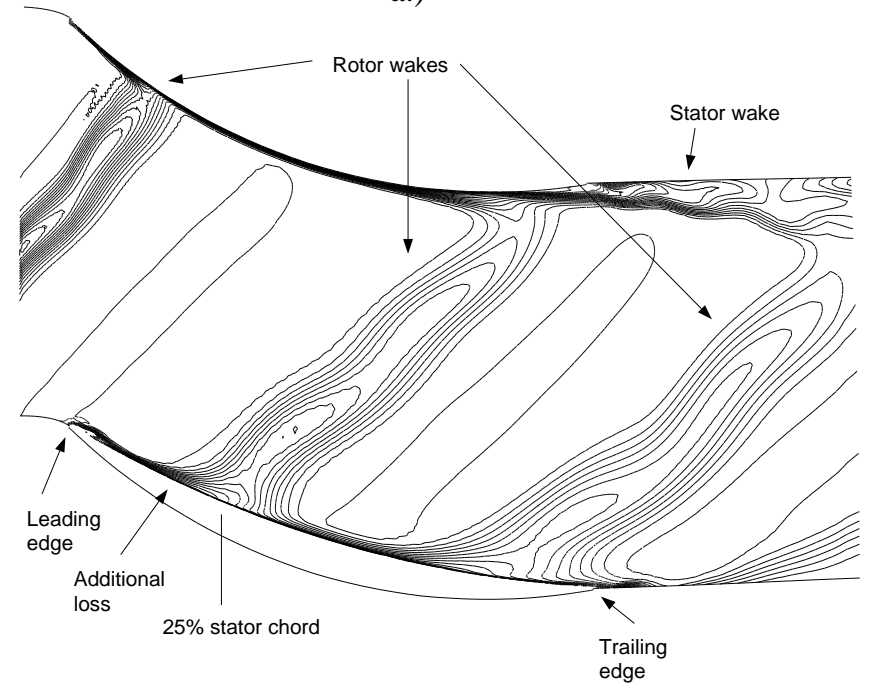

b.)

Figure 12. Stator 37 at an instant in time: a.) Disturbance velocity vectors. b.) Entropy contours.

APNASA and TURBO at the rotor trailing edge.

The influence of the rotor wakes on stator loss production is of greater importance. Figure 14 shows the variation of stator unsteady loss as a function of the rotor wake axial velocity deficit entering the stator at $50 \%$ span. The loss is normalized by the stator time average loss. The axial velocity deficit is normalized by the free stream axial velocity. Even at peak efficiency the stator shows a time variation of loss due to the interaction of the rotor wakes with the stator boundary layer and stator leading edge. The rotor wakes were already shown to increase the time average stator loss at peak efficiency. Results for the near stall case are similar.

The $\mathrm{x}$-axis scale ranges of Figures 13 and 14 represent an estimate of the range of interaction strength for moderate to 


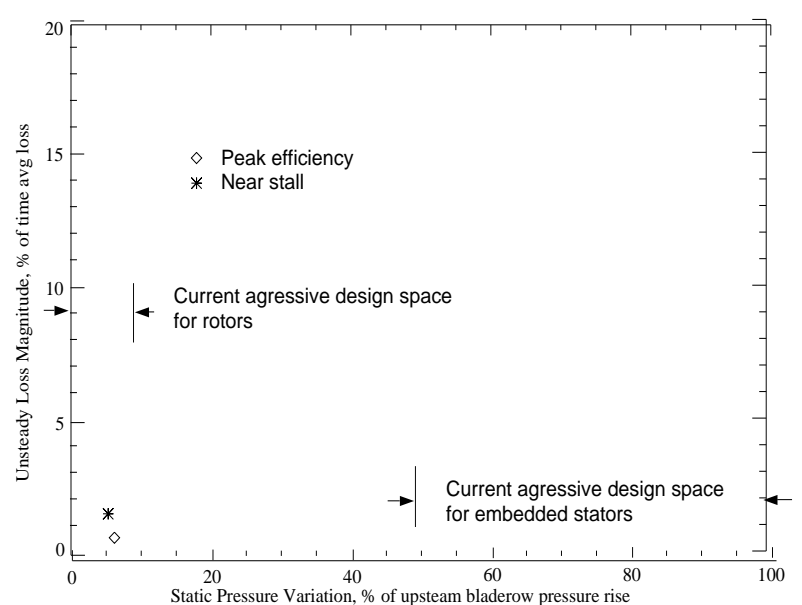

Figure 13. Unsteady loss variation in a blade row due to a downstream static pressure variation.

highly loaded blading. The stage $35 / 37$ design is at the low end of these parameter ranges and the losses due to interactions are generally small. In some cases, contemporary HP compressor designs have interaction strengths much larger than Stage 35/37 and may suffer from greater interaction losses. For example, figure 13 also includes the range of exit static pressure variation magnitude for embedded stators ahead of transonic rotors. No data are currently available to determine the loss versus interaction strength trend in this region. It is currently unknown if losses due to interactions increase dramatically once a threshold interaction strength is reached or if there is a linear relationship between loss and interaction strength. Detailed loss analysis of more machines will be required to determine this.

\section{CONCLUSIONS}

A detailed set of LDV data was used to confirm the fidelity of an unsteady simulation of a transonic compressor stage. The kinematics of the velocity field were accurately simulated and the unsteady simulation was then used to assess changes in loss production due to unsteady blade row interaction mechanisms.

Rotor loss production is not significantly affected by the varying back pressure due to the presence of the stator. The influence of the stator back pressure variation does not extend upstream of $80 \%$ rotor chord and the change in loss production is small for the last $20 \%$ chord of the blade in the peak efficiency case. In the near stall case the rotor clearance flow is no longer steady in the relative frame but did not contribute any significant additional loss. There was no attempt to consider time average changes in rotor back pressure due to time average changes in stator loss. The time variation of rotor loss is correlated with back pressure variation. However, it is unknown if loss production in an embedded stator is effected by downstream static pressure variations.

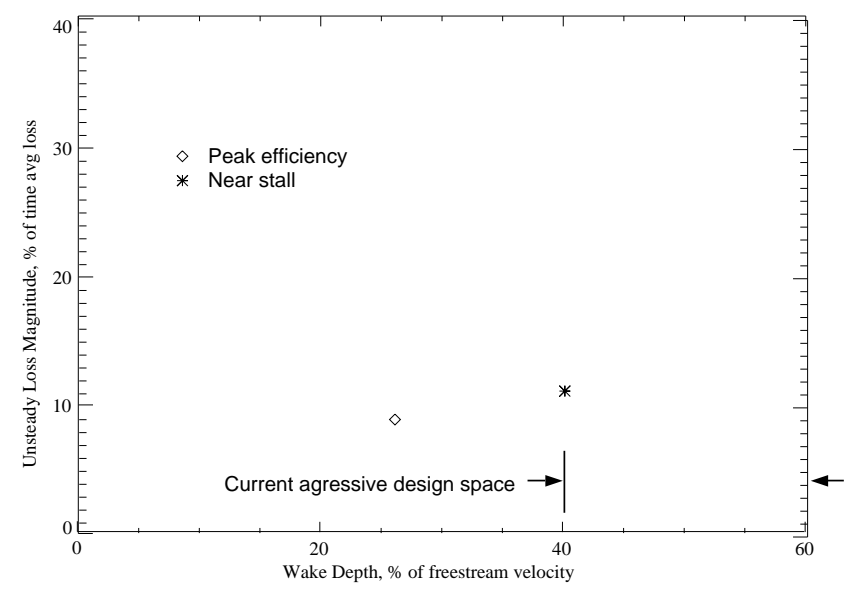

Figure 14. Unsteady loss variation in the stator due to the rotor wakes.

Time average stator loss is increased due to the rotor wake/ stator boundary layer interaction and rotor wake/stator leading edge interaction. The distribution of losses in the stator has changed significantly with losses increasing in the pressure surface boundary layer and core flow for the unsteady calculation. Interaction of the rotor clearance flow with the stator clearance flow did not produce any increase in time average loss production in this case. The time variation of stator loss is correlated with rotor wake depth to provide some guidance as to the magnitude of loss production changes.

\section{REFERENCES:}

1. Kemp, N. H., and Sears, W. R., "On the Wake Energy of Moving Cascades," Journal of Applied Mechanics, June 1956, pp. 262-268.

2. Hathaway, M. D., "Unsteady Flows in a Single-Stage Transonic Axial Flow Fan Stator Row," NASA TM 88929, December 1986.

3. Smith, L. H. Jr., 1996 in "Discussion of ASME Paper No. 96-GT-029: Wake Mixing in Axial Flow Compressors," 1996 ASME Turbo Expo, Birmingham, England, June 1013.

4. Van Zante, D. E., "Study of a Wake Recovery Mechanism in a High-Speed Axial Compressor Stage," PhD Dissertation and NASA CR-1998-206594, February 1998.

5. Ding, K., "Flow Measurements Using a Laser-Two-Focus Anemometer in a High-Speed Centrifugal and a Multistage Axial Compressor," Engineering Applications of Laser Velocimetry, ASME Winter Annual Meeting, Phoenix Arizona, November 1982. 
6. Williams, M. C., "Inter and Intrablade Row Laser Velocimetry Studies of Gas Turbine Compressor Flows," Journal of Turbomachinery, Vol. 110, July 1988, pp. 369-376.

7. Ottavy, X., Trebinjac, I., and Vouillarmet, A., "Analysis of the Inter-Row Flow Field Within a Transonic Axial Compressor: Part 1-Experimental Investigation Part 2-Unsteady Flow Analysis," Journal of Turbomachinery, Vol. 123, January 2001, pp. 49-63.

8. Estevadeordal, J., Gogineni, S., Goss, L., Copenhaver, W., and Gorrell, S., "Study of Flow-Field Interactions in a Transonic Compressor Using DPIV,” AIAA Paper No. 00-0378, AIAA Aerospace Sciences Meeting and Exhibit, Reno, Nevada, January 2000.

9. Berreby, R., Le Guevel, A., and Grisch, F., "Non-Intrusive Temperature Measurements in a Transonic Axial Compressor Using Spontaneous Rotational Raman Spectroscopy," ASME Paper No. 2001-GT-0330, IGTI Turbo Expo 2001, New Orleans, Louisiana, June 2001.

10. Epstein, A. H., Giles, M. B., Shang, T., and Sehra, A. K., "Blade Row Interaction Effects on Compressor Measurements," AGARD Unsteady Aerodynamic Phenomena in Turbomachines, AGARD-CPP-468/469, February 1990.

11. Valkov, T. V. and Tan, C. S., "Effect of Upstream Vortical Disturbances on the Time-Average Performance of Axial Compressor Stators: Part 1- Framework of Technical Approach and Wake-Stator Blade Interactions and Part 2 Rotor Tip Vortex/Streamwise Vortex-Stator Blade Interactions," ASME Paper Nos. 98-GT-312 and 98-GT-313, IGTI Turbo Expo 1998, Stockholm, Sweden, June 1998.

12. Capece, V., Private communication, July 2000.

13. Van Zante, D. E., Adamczyk, J. J., Strazisar, A. J., and Okiishi, T. H., 1997, "Wake Recovery Benefit in a High-Speed Axial Compressor,” ASME Paper No. 97-GT-535.

14. Reid, L. and Moore, R. D., "Design and Overall Performance of Four Highly Loaded, High-Speed Inlet Stages for an Advanced High-Pressure Ratio Core Compressor," NASA TP 1337, October 1978.

15. Adamczyk, J. J., Celestina, M. L., Beach, T. A., and Barnett, M., "Simulation of Three-Dimensional Viscous Flow Within a Multistage Turbine," Journal of Turbomachinery, Vol. 112, 1990, pp. 370-376.

16. Shabbir, A., Zhu, J., and Celestina, M. L., "Assessment of Three Turbulence Models in a Compressor Rotor," ASME Paper No. 96-GT-198, ASME Turbo Expo 1996, Birmingham, England, May 1996.
17. Van Zante, D. E., Strazisar, A. J., Wood, J. R., Hathaway, M. D., and Okiishi, T. H., "Recommendations for Achieving Accurate Numerical Simulation of Tip Clearance Flows in Transonic Compressor Rotors," Journal of Turbomachinery, Vol. 122, October 2000, pp. 733-742.

18. Chen, J. P. and Briley, W. R., "A Parallel Flow Solver for Unsteady Multiple Blade Row Turbomachinery Simulations," ASME Paper No. 2001-GT-0348, IGTI Turbo Expo 2001, New Orleans, Louisiana, June 2001.

19. Chen, J. P., Celestina, M. L., and Adamczyk, J. J., "A New Procedure for Simulating Unsteady Flows Through Turbomachinery Blade Passages," ASME Paper No. 94-GT-151, IGTI Turbo Expo 1994, Den Hague, Netherlands, May 1994.

20. Beach, T. A. and Hoffman, G., "IGB Grid: User's Manual (A Turbomachinery Grid Generation Code)," NASA Contractor Report 189104, January 1992.

21. Dunham, J., editor, "CFD Validation for Propulsion System Components," AGARD-AR-355, May 1998.

22. Denton, J. D., "Lessons from Rotor 37," Presented at the Third International Symposium on Experimental and Computational Aerothermodynamics of Internal Flows (ISAIF), Beijing, China, September 1-6, 1996.

23. Fundamentals of Classical Thermodynamics, Van Wylen, G. J. and Sonntag, R. E., John Wiley and Sons, 1986.

24. Car, D., private communication, September 2000.

25. Jennions, I.K. and Adamczyk, J.J., "Evaluation of the Interaction Losses in a Transonic Turbine HP Rotor/LP Vane Configuration," Journal of Turbomachinery, Vol. 119, No. 1, 1997, pp. 68-76.

26. Sanders, A.J., Papalia, J., and Fleeter, S., "Multi-Blade Row Interactions in a Transonic Axial Compressor Part 1: Stator Particle Image Velocimetry (PIV) Investigation," Paper No. 2001-GT-0268, Presented at ASME Turbo Expo 2001, New Orleans, Louisiana, June 2001. 
Public reporting burden for this collection of information is estimated to average 1 hour per response, including the time for reviewing instructions, searching existing data sources, gathering and maintaining the data needed, and completing and reviewing the collection of information. Send comments regarding this burden estimate or any other aspect of this collection of information, including suggestions for reducing this burden, to Washington Headquarters Services, Directorate for Information Operations and Reports, 1215 Jefferson Davis Highway, Suite 1204, Arlington, VA 22202-4302, and to the Office of Management and Budget, Paperwork Reduction Project (0704-0188), Washington, DC 20503.

\begin{tabular}{|l|l|l}
\hline 1. AGENCY USE ONLY (Leave blank) & $\begin{array}{c}\text { 2. REPORT DATE } \\
\text { March } 2003\end{array}$ & $\begin{array}{r}\text { 3. REPORT TYPE AND DATES COVERED } \\
\text { Technical Memorandum }\end{array}$ \\
\hline
\end{tabular}

4. TITLE AND SUBTITLE 5. FUNDING NUMBERS

Blade Row Interaction Effects on the Performance of a Moderately Loaded NASA Transonic Compressor Stage

6. AUTHOR(S)

WBS-22-714-03-54

Dale E. Van Zante, Wai-Ming To, and Jen-Ping Chen

7. PERFORMING ORGANIZATION NAME(S) AND ADDRESS(ES)

National Aeronautics and Space Administration

John H. Glenn Research Center at Lewis Field

Cleveland, Ohio 44135-3191

8. PERFORMING ORGANIZATION REPORT NUMBER

E-13781

9. SPONSORING/MONITORING AGENCY NAME(S) AND ADDRESS(ES)

10. SPONSORING/MONITORING AGENCY REPORT NUMBER

National Aeronautics and Space Administration

Washington, DC 20546-0001

NASA TM-2003-212180

GT-2002-30575

11. SUPPLEMENTARY NOTES

Prepared for the Turbo Expo 2002 cosponsored by the American Society of Mechanical Engineers and the International Gas Turbine Institute, Amsterdam, The Netherlands, June 3-6, 2002. Dale E. Van Zante, NASA Glenn Research Center; Wai-Ming To, AP Solutions, Inc., Cleveland, Ohio 44135; and Jen-Ping Chen, Mississippi State University, Mississippi State University 39762. Responsible person, Dale E. Van Zante, organization code 5810, 216-433-3640.

12a. DISTRIBUTION/AVAILABILITY STATEMENT

12b. DISTRIBUTION CODE

Unclassified - Unlimited

Subject Category: 07

Distribution: Nonstandard

Available electronically at http://gltrs.grc.nasa.gov

This publication is available from the NASA Center for AeroSpace Information, 301-621-0390.

13. ABSTRACT (Maximum 200 words)

Blade row interaction effects on loss generation in compressors have received increased attention as compressor workper-stage and blade loading have increased. Two dimensional Laser Doppler Velocimeter measurements of the velocity field in a NASA transonic compressor stage show the magnitude of interactions in the velocity field at the peak efficiency and near stall operating conditions. The experimental data are presented along with an assessment of the velocity field interactions. In the present study the experimental data are used to confirm the fidelity of a threedimensional, time-accurate, Navier Stokes calculation of the stage using the MSU-TURBO code at the peak efficiency and near stall operating conditions. The simulations are used to quantify the loss generation associated with interaction phenomena. At the design point the stator pressure field has minimal effect on the rotor performance. The rotor wakes do have an impact on loss production in the stator passage at both operating conditions. A method for determining the potential importance of blade row interactions on performance is presented.

14. SUBJECT TERMS

Machines; Compressing; Air; Fluids 15. NUMBER OF PAGES 18

\begin{tabular}{|c|c|c|}
\hline $\begin{array}{c}\text { 17. SECURITY CLASSIFICATION } \\
\text { OF REPORT } \\
\text { Unclassified }\end{array}$ & $\begin{array}{c}\text { 18. SECURITY CLASSIFICATION } \\
\text { OF THIS PAGE } \\
\text { Unclassified }\end{array}$ & $\begin{array}{c}\text { 19. SECURITY CLASSIFICATION } \\
\text { OF ABSTRACT } \\
\text { Unclassified }\end{array}$ \\
\hline
\end{tabular}

